\title{
UNA UTOPIA ESPAÑOLA EN BUSCA DE AUTOR: SINAPIA. Historia de una equivocación. Indicios para un acierto.
}

\author{
Por François LOPEZ \\ Universidad de Burdeos
}

En 1975 aparecia entre los fondos del Archivo del Conde de Campomanes, recién ordenados y catalogados por don Jorge Cejudo López $z^{(1)}$, dos textos de extraordinario interés, tanto para los estudiosos que se interesan en los orígenes de la llustración como para los eruditos que han ido señalando las influencias y los ecos del pensamiento de Tomás Moro en España. El primero de los textos encontrados es en efecto una utopia perfectamente constituída, rigurosamente conforme con las leyes formales que definen el género creado por una de las más admirables figuras del Renacimiento.

Percatándose del valor excepcional de estos manuscritos, un investigador canadiense, el profesor Stelio Cro, de McMaster University, que había estado investigando sobre el nacimiento de ciertos mitos de la Conquista de América, como el de los tesoros de El Dorado y la Ciudad de los Césares, proporcionó con la mayor brevedad una edición de ambas obras: Sinapia y un complementario Discurso de la educación, con una copiosa introducción y numerosas notas(2).

Al año siguiente se publicaba una importante reseña de este libro en Moreana, debida a Francisco López Estrada(3), y casi al mismo tiempo salía en Madrid otra edición de Sinapia (sin el Discurso de la educación) con prólogo y notas de Miguel Avilés(4). Aparentemente no conocía Miguel Avilés los trabajos de Stelio Cro. En cambio pudo éste ver la edición de Avilés cuando, en 1976, tras efectuar nuevas investigaciones en el Archivo del 
Conde de Campomanes, descubrió y publicó otros dos manuscritos de la misma e inconfundible letra que el original de Sinapia: anotaciones al Journal des Sçavans (años 1682 y 1685), y una lista de "Libros que faltan en la librerías(5).

Las anotaciones al Journal des Sçavans constituian para Stelio Cro un elemento decisivo en lo que se refiere a la datación de la serie de textos por él descubiertos. En efecto, los volúmenes de los que había sacado apuntes el autor de Sinapia eran del año 1682, las anotaciones que procedian de números posteriores del Journal habian sido escritas por otra mano. Estas observaciones minuciosamente consignadas por Cro, y el hecho que no aparecía en Sinapia ni el Discurso ni una sola alusión a cualquier realidad posterior al siglo XVII, le inducian a proponer para todo el corpus de textos considerado una fecha muy temprana: "Therefore we could conclude that the date around which our anonymous author writes is 1682. In fact this date would accomodate all the other manuscripts as wellw(6). Todo esto se oponía radicalmente a lo que Miguel Avilés habia escrito sobre la datación y los posibles autores de Sinapia. Según este erudito, la primera utopía española era una obra de la época de las Luces y su autor podía haber sido el propio Campomanes.

Es de lamentar que los dos libros de Cro hayan tenido por razones puramente editoriales tan escasa difusión en España. Dos recensiones, la ya señalada de Francisco López Estrada y otra de Amancio Labandeira Fernández(7), han subrayado la importancia del descubrimiento de Sinapia, poniendo de realce las relaciones que existen entre el contenido de esta obra y el ideario de la llustración, pero sin hacer resaltar el interés mucho mayor que cobra tal escrito al anticiparse en más de medio siglo a la publicación del Teatro crítico de Feijoo según los argumentos presentados por Cro.

Mientras tanto Sinapia se fue difundiendo ampliamente en la edición de Miguel Avilés, y nadie ha planteado verdaderamente los problemas de datación y atribución que suscita dicha obra. Por eso ha sido más que útil, preciso, que Stelio Cro presentara una síntesis de sus trabajos y repitiera sus conclusiones en una revista española: Cuadernos para Investigación de la Literatura Hispánica (2-3, 1980, p. 27-38).

Hoy día los eruditos españoles que mejor conocen la literatura utópica se inclinan a favor de la tesis de Cro, es decir, esencialmente, a favor de una datación muy temprana de Sinapia. Puede comprobarse este hecho en las más recientes publicaciones de Francisco López Estrada y sobre todo de Pedro Alvarez de Miranda(8).

Al intervenir ahora en este debate, no nos proponemos estudiar los rasgos genéricos ni todo el contenido de Sinapia, sino volver sobre dos problemas: el de la época en que se escribió la obra, y el de la personalidad e identidad de su autor. 
Digamos de entrada que en cuanto a una datación muy temprana, estamos fundamentalmente de acuerdo con Stelio Cro. Su argumentación basada en las referencias históricas que se hallan diseminadas en el texto, la importancia decisiva que cobran las anotaciones al Journal des Sçavans de 1862, bastarian de por si para probar que no son estos escritos los de un llustrado, sino de un "forerunner of the Enlightenment in Spain". Según estos datos, la composición de Sinapia puede situarse, con el más alto grado de verosimilitud, en los dos últimos decenios del reinado de Carlos II, no forzosamente en 1682, a nuestro parecer, (ya que un periódico científico como el Journal des Sçavans podía conservar todo su interés durante varios años), pero sí en un momento que no debe de ser muy posterior. En esa época empieza en España lo que hemos Ilamado, a falta de más exacta formulación, "el tiempo de los novatores". Y salta a la vista cuando leemos Sinapia, el Discurso, las anotaciones al Journal des Sçavans que el autor de estos escritos tiene las mismas curiosidades que los demás novatores españoles y es un partidario de la ciencia moderna, todavia cartesiana, prenewtoniana, experimental en todo caso. En los últimos decenios del XVII hubo, como es bien sabido ahora, activos grupos de novatores en Madrid, Sevilla, Valencia, Zaragoza y Barcelona(9). Es muy plausible que a uno de esos grupos perteneciera el autor de Sinapia.

Pero si no es difícil situarlo en un grupo socio-cultural y en una época, más arduo es encontrar en lo que escribe unos rasgos inconfundibles que permitan descubrir su identidad. Lo que sí es posible, es delinear su personalidad utilizando el conjunto de los textos que nos han sido conservados.

Lo que más nos Ilama la atención en éstos es que el autor aúna con la mayor naturalidad su adhesión a la ciencia moderna (considerada como heterodoxa y abominable por la mayoria del clero español de su tiempo y por todos los claustros) con un humanismo cristiano que resplandece con el acendrado fervor que pudo ser el de un Erasmo, de un Moro, de un Vives. Véase lo que representa la religión en Sinapia:

"La religión, en toda la península, es la cristiana, sin hipocresía, superstición ni vanidad. La disciplina es la que se observaba en el tercer y cuarto siglo. No pueden explicarse los misterios, sino con los términos que los explica la Sagrada Escritura, contentándose con creerlos, sin querer saber el modo. No admiten en estas materias la menor novedad, estando prohibido inventar nuevas devociones sin la aprobación del Sínodo, lo cual aprueba rarísima vez (...).

Ayúdanse, en el ministerio de la palabra de Dios y administración de los sacramentos, de los diáconos, a los cuales ayudan los subdiáconos ( $y$, para la instrucción de las mujeres, las diaconesas) y, para el cuidado de los templos, del canto y 
las lecciones públicas, los acólitos, cantores y lectores. Y este es el orden de todos los eclesiásticos.

No pueden ser acólitos si no son de doce años y saben leer y escribir el sinapiense. No pueden ser cantores si no han ejercido el oficio de acólitos tres años y saben el canto; no pueden ser lectores si no han ejercido el cargo de cantores cuatro años, ni ser ordenados de subdiáconos si no han sido lectores cinco años y saben el hebreo y el griego; ni ser ordenados de diáconos si no han sido subdiáconos seis años y saben muy bien el hebreo y el griego; ni sacerdotes si no han sido diáconos diez años y saben la Santa Escritura e historia eclesiástica (...).

Todos los oficios se hacen en lengua sinapiense y las lecciones públicas de la Santa Escritura (...).

Solos los eclesiásticos pueden enseñar la ciencia divina, pero los seglares pueden muy bien estudiarla y escribir sobre ella, pero no dar a luz los escritos sin la aprobación de la Iglesia(10).

En dos ocasiones apunta Stelio Cro la sugestión de que estas normas de vida religiosa bien pueden ser la de un protestante. Pensamos al contrario que el reivindicar un fundamentalismo bíblico era muy propio de una élite católica que no podía ver sin aflición la proliferación de cultos, creencias, supersticiones a la que había dado lugar en España una fe mal entendida. "Another indication of the Protestant inspiration of the author is this reading in the "vulgar" of the Holy Scriptures. National languages were adopted to read the Holy Scriptures during the Protestant Reformation in Germany, England and Holland (11). Otro argumento que puede utilizarse a favor de una tesis contraria: del Renacimiento a la llustración se mantuvo en España un ideal que llamaremos erasmiano para más comodidad de conocimiento de la Biblia en las lenguas madres, en la Vulgata, en lengua vernácula(12).

Interés apasionado por el conocimiento, por las humanidades y la ciencia moderna, y además fundamentalismo cristiano, deseo de resucitar la más antigua y pura disciplina de la Iglesia: he aquí una configuración intelectual y espiritual que no fue la de todos los novatores españoles, para quienes la ciencia moderna era lo que importaba. En cuanto al humanismo cristiano, su supervivencia o resurgimiento está abundantemente atestado en Valencia cuando Mayáns empieza a publicar sus primeras obras importantes. En otros sitios no parece haber dado frutos esa corriente espiritual.

En 1980, cuando tuvimos la oportunidad de leer los trabajos de Stelio Cro, las observaciones que acabamos de formular nos llevaron a pensar 
que el autor de Sinapia pudo haber sido un novator valenciano. Esta hipotesis cobraba más plausibilidad al considerar algunos detalles del texto que no parecían haber llamado la atención de sus dos editores. Nos referimos a ciertas palabras usadas por el anómimo autor de nuestra utopía para describir el país mítico del que soñaba. Varias veces evoca una geografía ideal con elementos típicamente españoles: p. 76: "acequias", "azudes", "norias»; p. 82: "noria»; p. 84: "huerta»; p. 88 otra vez: "acequias", "norias". Y en la página 99: "en las alturas de toda la costa, sus atalayas, para avisar con fuego o humo la venida de forasteros". Todo esto hace pensar irresistiblemente en el litoral levantino. $Y$ hay otros detalles que confirman que el autor "imagina" a partir de recuerdos, de cosas vistas: p. 104: "A las mujeres se les permiten vestidos de colores varios $y$, cuando van fuera de casa, capucha a la catalana, blanca el verano y negra el invierno". Quien esto escribe es catalán o valenciano, e involuntariamente lo manifiesta en este otro trozo: p. 133: "Cuántos de los que trabajan se emplean en ejercicios o inútiles o perjudiciales, como en la multitud de gente que ocupa a los tribunales, la infinidad de soldados que la ambición mantiene en guerras no necesarias, plateros, joyeros, guanteros, parruqueros, cocheros, botilleres, fabricadores de puntas y encajes, banqueros, bordadores, etc., todos inútiles y fomentadores de la superfluidad, madrastra de la abundancian. Es obvio que parruqueres y botilleres son palabras catalanas o valencianas, y en la fotocopia del manuscrito original que tenemos a la vista puede comprobarse que la trascripción de Miguel Avilés es la correcta(13).

Sabiendo cuáles eran las aspiraciones espirituales del autor de Sinapia, qué conocimientos hubiera querido privilegiar (el de la Biblia, en griego, hebreo y lengua vernácula), la afición que manifestaba por un arte depurado, clásico; su interés por el teatro, la arquitectura, su curiosidad abierta a todos los inventos y experiencias de la ciencia moderna; sentando como hipótesis muy plausible que él habia sido un novator valenciano, y teniendo por fin que considerar que Sinapia se compuso en los dos últimos decenios del siglo XVII, tratamos hace dos años con la sola ayuda de los libros de nuestra biblioteca de descubrir quién pudo ser ese personaje.

Nuestras primeras indagaciones nos proporcionaron una serie de indicios que insistentemente apuntaban hacia un autor poco conocido de fines del siglo XVII y principios del XVIII: Manuel Marti, deán de Alicante, a cuya figura y a cuyos escritos acababan de dedicar excelentes trabajos Antonio Mestre y Luis Gil(14).

Nacido en 1663, había llegado Marti a la edad adulta por las fechas que asigna Stelio Cro a la composición de Sinapia (de 1682 en adelante), y sabemos por la Martini Vita, publicada por Mayáns cuando vivía aún el deán (1735), que éste escribió en su juventud numerosas poesias, incluso una silva "a imitación de la primera de Luis de Góngora», pero muy pronto, 
dice Mayáns, "rechazando aquella manera enigmática de escribir, se inclinó de forma maravillosa por la transparencia y claridad del lenguaje. $Y$ de ahí resulto que no parezca que expone las cosas, sino que las presenta como pintadas a la vista, no sólo en la poesia, que es una pintura que habla, sino también en prosaw(15).

De la cultura de Martí nos ofrece un buen panorama su correspondencia con Mayáns. La medicina, la ciencia y la filosofía modernas ("Pedro Gasendo es el Príncipe de la verdadera philosophían), el derecho, la historia antigua, la literatura griega y latina, la numismática, la arqueología, la filosofía apasionaban al deán que parece haber tenido singulares conocimientos en todos esos ramos del saber. Eminente helenista, se habia empeñado durante una primera estancia en Roma (1686-1696) en aprender el hebreo, y lo consiguio(16). Añádase que era Martí gran lector de la Biblia, y habrá que reconocer que el parecido entre el deán de Alicante y el autor de Sinapia es realmente extraordinario.

Volviendo a estudiar la utopía recién descubierta, nos fijamos en unos detalles que antes no nos habían llamado la atención: las ciudades que se describian en Sinapia, algo tenian de villas romanas, con "su patinejo enmedio, con fuente o pozo; puerta a la calle y al jardín, y pórticos con galería" (p. 82). En cuanto a los templos sinapienses, albergaban en su recinto uel cimenterio común. Este es subterráneo, bajándose a él con cinco escalones por cuatro puertas que hay enmedio de las cuatro caras del cuadrado. Compónese de cuatro bóvedas, que le atraviesan en cruz, dejando en el centro (que corresponde debajo del altar) una capilla redonda con su altar. Y por las paredes de las bóvedas están los sepulcros, en nichos como los de las catatumbas" (p. 95). Esta última palabra, catacumba, hoy conocida de cualquier individuo de mediana cultura, era muy poco usada a fines del siglo XVII y principios del XVIII. Desde luego no está en el Diccionario de Autoridades. De lo que eran las catacumbas, sólo podían tener una idea precisa los pocos arqueólogos que las habian visitado en Roma. Un humanista como Mayáns, muy versado en historia antigua y de inmenso saber libresco, necesitó las luces de Manuel Martí para saber qué aspecto tenian esos vestigios de la antigüedad cristiana:

"Es cierto que las catacumbas o cementerios de los mártyres antiguos se extienden muchísimo. Y el famoso Raphael Fabretti, monseñor Ciampini y Joseph de Juliis, me aseguraron que alguno de ellos llegaba hasta el mar que está a 4 leguas de Roma. Y no hay que extrañar se extendieran tanto, siendo el refugio y habitación de los cristianos y Sumos Pontifices, y sepulturas de infinitos mártires que contínuamente padecian martirio. Y Vm. se engaña en creer que allí hay edificios; pues sólo está cavada la tierra y hechas unas como callejuelas, sin que haya cosa de argamasa ni piedras(17). 
Otro hecho incitaba a atribuir a Martí la paternidad de Sinapia y del Discurso de la educación. En dicho Discurso leemos cómo ha de explicarse a los niños lo que es el espíritu ("cosa que piensa; pensar es sentir, imaginar, conocer y querer») (p. 111), y qué son las pasiones ("Ay en nuestra alma ciertos pensamientos que llamamos pasiones, las quales son necesaríssimas para nuestra conservación; como su demasía es dañossísima»). Atinadamente observó Stelio Cro que al respecto se inspiró el autor del Traité des passions de Descartes. Pues bien, fue Manuel Martí el único español de su tiempo que escribió un tratado Sobre las pasiones, obra compuesta en los primeros años del siglo XVIII(18).

En cuanto al ideal igualitario que resplandece en Sinapia, no cabe duda que pudo ser compartido por el deán de Alicante, que en sus cartas denuncia la avaricia, "apetito infame de riquezas" (p. 224) y hace el elogio de la vida frugal y sencilla. Por otra parte había sido Martí en Roma miembro de la Academia de los Árcades, cuyo reglamento estableciera Juan Vicente Gravina, y sobre este reglamento hace Luis Gil observaciones por cierto muy notables:

"Constaba el reglamento de doce puntos y estaba escrito en latin arcaico como la ley de las XII Tablas. La primera "ley" atribuía la summa potestas al commune de los Árcades; por la segunda se preveía el nombramiento democrático de un custos rebus gerundis et procurandis con un mandato cuadrienal; la tercera asignaba a un custodis vicarius y a un colegio de 12 miembros la asistencia en las funciones de gobierno al presidente; la cuarta disponía un sistema de votación secreta para la elección de cargos; la quinta señalaba la obligación del presidente de comunicar al pleno de los Árcades las diligencias tomadas por el comité directivo, etc. Este reglamento de carácter estrictamente democrático revela el genio jurídico de Gravina, que no en vano renovó la enseñanza del derecho y fue un precursor de Montesquieu»(19).

Por fin recordemos las últimas líneas de Sinapia y la profunda amargura que expresan:

"Finalmente, el fin de este gobierno no es dilatar su dominio, enriquecer sus súbditos ni extender su fama, sino hacerlos vivir en este mundo justa, templada y devotamente, para hacerlos felices en el otro. Sólo se estima la verdadera virtud. Sólo se procura la verdadera honra que nace de ella y sólo se apetece el verdadero deleite, que es el que siente una conciencia que nos asegura haber hecho en todo nuestro deber. Todo lo cual sólo se puede conseguir en una nación sencilla, que carece de las maliciosas máximas de la politica interesada, de la soberbia que engendra la nobleza hereditaria, de la desigual- 
dad de ricos y pobres y que ignora la artificiosa variedad de regalos y comodidades que ha inventado la poltronería y que no está envilecida con la acostumbrada sujeción y está hecha al trabajo y a la necesidad.

Mas, como la corrupción del hombre es tan grande, no han faltado naturales aviesos, que han procurado alterar el gobierno, introduciendo la propiedad, la novedad de usos, la dominación, la moneda, la estimación de las riquezas y el ocio, la vanidad de la sangre, etc., pero se ha remediado con la prontitud del castigo, ayudada de los pocos compañeros que han hallado de su opinión, por lo bien instruidos que están desde niños en las conveniencias que gozan en su gobierno y los inconvenientes y desdichas que experimentan otras naciones en el contrario.

Finalmente se observa que, así en el sitio como en todo to demás, es esta península perfectísimo antípode de nuestra Hispaña».

Esta vehemencia al señalar las plagas de España, se encuentra casi constantemente en las cartas de Martí a Mayáns. Recojamos algunas de sus palabras: "el desaliño y bestialidad de nuestra nación" (p. 155); "vivir como se vive en España en Materia de letras. A ciegas». (p. 164); “España, en que se malogran los mayores ingenios sumergidos en el cenegal de la barbarie y escolásticos delirios (...) Todo el amor es al lucro, nada a la ciencia» (p. 192); "esta bárbara nación» (p. 198); "Ya que el rigor de mi destino me ha hecho nacer y vivir en esta tierra bárbara" (p. 205); "verá el mundo mi desesperación por haber nacido en esta bárbara región".

Tantas semejanzas con el autor de Sinapia y el deán Martí eran verdaderamente impresionantes, tanto más cuanto que podríase añadir algún que otro punto común a los ya señalados. Una frase que encontramos en una carta de Martí acabo de convencernos de que él era el hombre a quien buscábamos. El 6 de febrero de 1733, respondiendo a Mayáns que por aquel entonces residia en Madrid y disponía de muchas obras del deán del que éste a veces ni siquiera se acordaba, escribía esto a Martí: "No entiendo lo que Ud. me quiere decir con aquellas palabras: de la vision del Etíope no me dice $U d$. palabra. En explicándose responderé. Porque yo nunca tuve visión alguna o aparición de Etíope» (p. 272).

En efecto nunca habia tenido Martí visión alguna de Etíope. El sueño del que habla posteriormente a su discípulo y biografo no tiene la más mínima relación con Etíope. ¿Como pudo producirse esta confusión? Como el sueño ya aludido ha quedado literalmente plasmado en la Martini $\mathrm{Vi}$ ta, ha tenido Luis Gil que dar alguna aclaración al respecto, y puede notarse cierta perplejidad en su comentario: 
"Reproducción literal de la muy bella ficción literaria de Martí, en la que él familiarizado con la lectura de los clásicos grecolatinos encontrará todos los ingredientes que caracterizan al que he denominado en otras ocasiones «ensueño prostagmáticon. Por cierto que esta ficción se prestó a un curioso mal entendido de Mayáns. En una carta perdida de primeros de febrero de 1733 el deán debía de referirse a ello, provocando la curiosidad de su corresponsal. Martí replicaba el 6 de dicho mes (...). Dias después se aclaraba el equívoco: "La visión que Ud. desea saber, la verá en esa carta que escribí a Verona, al marqués de Maffei, que espero no desagradará a Ud. Solamente le suplico me la restituya bona fide, porque es el original y, si se pierde, se perdió todo»(20).

Pero de hecho, el equívoco, para nosotros, no quedaba bien aclarado. ¿Cómo pudo Mayáns, tan minucioso siempre, hablar de Etíope cuando en el sueño de Martí, que muy buena letra tenía, se trata de España?. He aquí el texto que literalmente transcribió don Gregorio:

"Cum ex continenti nocturni laboris agitatione fessus somno tandem me tradidissem, primo diłuculo visus mihi sum per quietem matronam intueri augustiore forma, dextra librum tenentem, sinistra expansa cuniculum. Quo ego symbolo facile cognovo eam speciem, quae ante oculos obversabatur, Hispaniam nostram repraesentare".

Este hecho, mínimo por supuesto, avivó nuestro interés porque recordábamos que los manuscritos de Sinapia y las anotaciones al Journal des Sçavans fueron catalogados por un poseedor desconocido bajo el título por cierto sorprendente de Historia Etiópica. La única relación que puede verse entre dicho título y los escritos descubiertos por Cro es que la primera anotación al Journal des Sçavans viene encabezada por esta referencia bibliográfica: Jobi Ludolphi historia Aethiopica. fol. Paris. Todo esto lo comenta Stelio Cro con su sagacidad habitual:

"The title of course would be a very current one in the seventeenth-century, since Heliodorus' homonymous byzantine novel was a major source of inspiration for many important writers, among them Cervantes and his Persiles. More important, the title would also have averted any suspicious eye from MSA (las anotaciones), labelled under such an innocent title. It is also indicative that MSS (Sinapia) and MSA would be listed togetherw21).

Pensamos que lo más plausible es que quien catalogó los manuscritos quiso sustraer a la curiosidad el texto de Sinapia considerando que podía parecer muy subversivo y atraer serios disgustos a su poseedor y a 
su autor. En nuestro edificio argumentativo, este nimio detalle cobraba una importancia fundamental ya que interpretábamos así los hechos: Mayáns, teniendo y ordenando las obras del deán de Alicante en Madrid, se encontró con Sinapia que ya llevaba por escudo el título de Historia Etiopica y quiso consultar a su autor sobre la oportunidad de su publicación, como solia hacerlo con otros escritos de Martí, entre los cuales no faltaban atrevidas sátiras. Así habia hecho don Gregorio con otras obras del deán que, de sus escritos de juventud no tenía a veces ningún recuerdo, sobre todo cuando no eran muestras de su talento de humanista, helenista y latinista.

Esa ha sido, esquemáticamente, la argumentación que presentamos a principios del año pasado en una conferencia que dimos en la Universidad de Alicante. Estábamos entonces totalmente convencidos de que la atribución a Martí de Sinapia y del Discurso de la educación era irrebatible.

Pero luego, teniendo en cuenta un elemento que nunca hubiéramos debido descartar, nos persuadimos que habiamos caído en una equivocación. En efecto todos los indicios que hemos reunido para atribuir Sinapia a Manuel Martí no bastan para salvar un obstáculo al que no prestamos la debida atención. El manuscrito de Sinapia no es una copia. Como lo subrayó Stelio Cro, el texto está escrito y enmendado muchas veces por una misma mano. Es decir que el autor fue el scriptor. Y la letra de los manuscritos no es la de Martí. Suponiendo incluso que su letra pudo cambiar mucho entre los últimos años del siglo XVII y la fecha de 1720 que es la de los más antiguos autógrafos suyos que hoy se conocen, es totalmente imposible que cambiara a este punto.

De un doble examen grafologico al que sometimos una xerocopia de unas páginas de Sinapia por una parte y de una carta de Marti por otra parte, recogimos las conclusiones siguientes: uno de los grafólogos consideraba que el scriptor de Sinapia no puede ser el de la carta. El otro dice que que si hay entre las diferentes muestras de letra un lapso de tiempo de más de veinte años, no puede concluir con certeza, pero que opina más bien que los manuscritos son de dos sujetos distintos, añadiendo que el scriptor de Sinapia fue seguramente un individuo ya entrado en edad o enfermo.

En conclusión, de todas nuestras observaciones sólo tienen plausibilidad las que atienen al origen valenciano (o a un "vivir" valenciano) del autor de Sinapia. La atribución de esa admirable utopía a Manuel Martí es altamente improbable. El hombre cuyo rastro seguimos solo podrá ser identificado si se realiza un cotejo de autógrafos. Esto supone un paciente trabajo en archivos y bibliotecas donde se conserven manuscritos de los novatores valencianos. 


\section{NOTAS:}

(1) J. Cejudo López, Catálogo del Archivo del Conde de Campomanes (Fondos Carmen Dorado y Rafael Gasset), Madrid, Fundación Universitaria Española, 1975.

(2) Sinapia. A Classical Utopia of Spain, edited by Stelio Cro with and appendix,McMaster University, 1975.

(3) Moreana, 52, 1.976, p. 53-56.

(4) Sinapia. Una utopia española del Siglo de las Luces, edición de Miguel Avilés, Madrid, Biblioteca de visionarios, heterodoxos y marginados, Editora Nacional, 1976.

(5) Cro, Stelio, A Forerunner of the Enlightenment in Spain, McMaster University, Hamilton, 1976.

(6) Ibid., p. 16.

(7) Revista Canadiense de Estudios Hispánicos, 1, 1976, p. 120-124.

(8) López Estrada, Francisco, Tomás Moro y España, Madrid, Editorial de la Universidad Complutense, 1980, p. 101-107; Alvarez de Miranda, Pedro, "Sobre utopias y viajes imaginarios en el siglo XVIII español", en Homenaje a Gonzalo Torrente Ballester, Salamanca, Biblioteca de la Caja de Ahorros y Monte de Piedad de Salamanca, Salamanca, 1981, p. 351-382.

(9) López Piñero, José María, Ciencia y técnica en la sociedad española de los siglos XVI y XVII, Barcelona, Labor, 1979 (Segunda parte).

(10) Todas las citas se harán según la edición de Miguel Avilés. Véase la p. 93.

(11) A Forerunner..., p. 82.

(12) López, François, Juan Pablo Forner et la crise de la conscience espagnole au XVIIle siècle, Bordeaux, Institut d'Etudes Ibériques et Ibéro-américaines de l'Université de Bordeaux, 1976 , p. 148 y s.

(13) Stelio Cro enmienda aqui el texto: "peruqueros" y "botilleros".

(14) Mayáns y Siscar, Gregorio, Epistolario, III, Mayáns y Marti, Transcripción, notàs y estudio preliminar de Antonio Mestre, Publicaciones del Ayuntamiento de Oliva, 5, Valencia, 1973; Emmanuelis Martini, ecclesiae alonensis decani, vita, scriptore Gregorio Maiansio, generoso valentino, Estudio preliminar, edición bilingüe y comentario de Luis Gil, Publicaciones del Ayuntamiento de Oliva, serie menor III, Valencia, 1977.

(15) Ibid. p. 61.

(16) Ibid. p. 67.

(17) Epistolario Mayáns y Marti, p. 305.

(18) Se publicó como apéndice en el Epistolario latino del deán, t. II, p. 229-254.

(19) Martini vita, ed. y trad. de Luis Gil, p. 324-325.

(20) Ibid., p. 411-412.

(21) Stelio Cro, A Forerunner..., p. 6. 